\title{
Potential threats for the auditing profession, audit firms and audit processes inherent in using emerging technology
}

\author{
Dale McGregor \\ Riley Carpenter \\ College of Accounting, University of Cape Town, South Africa
}

\section{Key words}

Artificial intelligence, audit, blockchain, big data, machine learning, robotics

\begin{abstract}
The audit profession currently faces several challenges to improve audit quality and efficiency. In response to these challenges, audit firms have invested considerably in implementing emerging technology. Although technological innovation may improve efficiency and effectiveness of operations, using these technologies creates several threats, which, if not adequately addressed by auditors, may harm audit quality, efficiency, and the professional development of the auditor. This paper performs a qualitative analysis of prior literature regarding the threats created by audit firms implementing emerging technology. These threats include concerns related to the integrity and security of data inputs, the auditor placing too much reliance on technology to the detriment of their professional development and exercise of professional judgement, a shortage of skills, the costs of technology implementation, disruptions to the status quo of the audit profession and auditing standards potentially being outdated. This paper adds value firstly by helping to determine how technology impacts the future of the auditing profession and secondly, by helping firms determine whether to invest in new technologies by providing a comprehensive overview of the threats resulting from such a decision.
\end{abstract}

\section{Introduction}

\section{Dawn of the Fourth Industrial Revolution}

Technological advances over time have improved mechanical production (Industry 1.0), distribution of electrical power generation (Industry 2.0) and the development of digital systems to automate routine tasks and duties (Industry 3.0) (Schwab, 2016; Veerankutty et al., 2018). These technical advances, particularly those in the field of computer science, have ushered in the Fourth Industrial Revolution (Industry 4.0), and created the processing speed and power for breakthroughs in new emerging technologies (Hashimoto et al., 2018) to allow humans and computers to collaborate and integrate in ways not previously thought possible (Schwab, 2016), thus allowing businesses to conduct their operations with greater efficiency and effectiveness (Beata, 2018; Schwab, 2016; Veerankutty et al., 2018). Audit firms are no different and accordingly have made significant investments, particularly the 'Big 4' audit firms, to implement these emerging technologies in their audit practices (Deloitte, 2020; EY, 2020a; KPMG, 2020; PwC, 2019). However, before audit firms can realise the full extent of the benefits from using emerging technology, they must be aware of and respond to the threats these emerging technologies present.

\section{The rationale for audit firms to implement emerging technologies}

Auditors are constantly challenged to reduce audit fees (Asthana et al., 2018) and improve audit quality (Botic, 2018; Harris, 2016) while managing a significant amount of work (Persellin et al., 2019) in limited time (Ferguson, 2016; Persellin et al., 2019) and with limited resources at their disposal (Persellin et al., 2019). To address these challenges, audit firms have explored using emerging technologies (Harris, 2017).

Furthermore, as audit clients adopt these emerging technologies to aid decision making in their businesses, auditors will need to adopt advanced analytics to address the risks arising from new but complex technologies (Alles, 2015; Appelbaum et al., 2017) and meet their client's expectations (Alles, 2015). 


\section{Research question}

By focusing on the emerging technologies covered most extensively in academic literature and mainstream media, this paper provides a detailed qualitative analysis to interrogate the following research question:

"How have the threats from emerging technologies such as artificial intelligence (AI) (including data analytics), robotics process automation and blockchain affected the auditing profession, audit firms and/or the audit process?"

To determine the scope for how this paper attempts to answer this question, a few broad terms in the research question need to be defined, specifically, "artificial intelligence", "robotics process automation" and "big data".

\section{Definitions}

\section{Artificial intelligence}

The Institute of Electrical and Electronics Engineers Standards Association Corporate Advisory Group defines AI in the IEEE Guide for Terms and Concepts in Intelligent Process Automation (2017:12) as:

"The combination of cognitive automation, machine learning, reasoning, hypothesis generation and analysis, natural language processing, and intentional algorithm mutation producing insights and analytics at or above human capability."

AI enables machines to think like humans and perform functions that require human intelligence such as problem-solving, recognition of text, speech and images, reasoning, and learning (Copeland, 2020). AI also allows computers to adapt to their environment (Copeland, 2020).

Hashimoto et al. (2018) categorise AI into four further divisions, namely machine learning, artificial neural networks, natural language processing and computer vision.

Machine learning is defined in the IEEE Guide for Terms and Concepts in Intelligent Process Automation (2017:14) as:

"Detection, correlation, and pattern recognition generated through machine-based observation of human operation of software systems along with ongoing self-informing regression algorithms for machine-based determination of successful operation leading to useful predictive analytics or prescriptive analytics capability."

Machine learning, at its core, focuses on how machines learn from data by recognising patterns in data to improve future performance (Alpaydin, 2016; Hashimoto et al., 2018).

Artificial neural networks, a branch of machine learning, simulate the human brain by receiving data inputs and then processing the data to produce an output (Deo, 2015). Its emergence has played a vital role in developing many AI applications (Hashimoto et al., 2018).

Natural language processing is an AI application regarding how computers process and analyse written or spoken language. Applications of natural language processing include its use in search engines, such as Google, speech and document categorisers and virtual assistants such as Apple's Siri (Quarteroni, 2018).

Computer vision emphasises how machines understand images and videos, thus emulating a human's ability to recognise objects and scenes. Popular computer vision applications include fingerprint recognition, motion capture, surveillance, optical character recognition and machine inspections (Szeliski, 2011).

\section{Robotic process automation}

Robotic process automation is defined in the IEEE Guide for Terms and Concepts in Intelligent Process Automation (2017:11) as:

"A preconfigured software instance that uses business rules and predefined activity choreography to complete the autonomous execution of a combination of processes, activities, transactions, and tasks in one or more unrelated software systems to deliver a result or service with human exception management."

In essence, robotic process automation allows rules-based human tasks to be automated by robots (Moffitt et al., 2018). 
Big data

Common features of "big data" definitions tend to encompass large data sets consisting of different types of data from various sources. However, Gandomi and Hader (2015) and Favaretto et al. (2020) note that there is no official "big data" definition.

Gartner (2012) defines "big data" as information assets that are high-volume, high-velocity and/or high-variety and which require new time and cost-efficient methods of data processing that result in greater insight, ability to make decisions and automating of processes.

Using this definition, Favaretto et. al (2020) explain that the definition of big data comprises three common characteristics, namely volume, velocity, and variety. Volume refers to a large amount of data but with no consensus on what is considered "big", while velocity refers to the exponential rate at which data is produced and processed. Lastly, variety denotes the different types of data that are accumulated from various sources such as administrative data, social media content, photographs, and videos. Gandomi and Haider (2015) argue that characteristics such as velocity and variety are equally important as volume.

Other definitions from internationally renowned organisations and bodies include the following: The National Science Foundation, established by the United States Congress, defines "big data" as:

"Large, diverse, complex, longitudinal, and/or distributed data sets generated from instruments, sensors, Internet transactions, email, video, click streams, and/or all other digital sources available today and in the future." (National Science Foundation, 2012:2)

"Data that challenge existing methods due to size, complexity, or rate of availability." (National Science Foundation, 2014:3).

The European Commission (2016:1) refers to "big data" as:

"Large amounts of different types of data produced from various types of sources, such as people, machines or sensors. This data could be climate information, satellite imagery, digital pictures and videos, transition records or GPS signals. Big Data may involve personal data: that is, any information relating to an individual, and can be anything from a name, a photo, an email address, bank details, posts on social networking websites, medical information, or a computer IP address."

Lastly, the Association of Certified Chartered Accountants (2020) defines "big data" as very sizeable data sets or collections of data that can be analysed specifically for patterns, trends, or linkages, with particular reference to human conduct and communications.

Other features such as versatility, vitality, exhaustivity and extensionality have also been considered as features of big data (Favaretto et al., 2020).

Certain academics and practitioners have incorporated the techniques used to analyse the data sets as part of the "big data" definition (Favaretto et al., 2020), however, Salijeni et al. (2018) distinguish those techniques as a separate concept referred to as "big data analytics".

For this paper, "big data" is used within the context of the three common characteristics provided by Favaretto et. al (2020) - volume, velocity, and variety - while the term "big data analytics" refers to the techniques for analysing the datasets, consistent with Salijeni et al. (2018).

\section{Research design}

This paper is structured as follows. The next section describes the methodology used; thereafter, the literature review identifies and discusses the key threats of artificial intelligence, big data analytics, robotics process automation and blockchain to audit firms, the audit industry, and the audit process.

The substantial number of threats facing audit firms poses a challenge in attempting to satisfy this paper's research question. Therefore, it focuses only on the key threats, which helps provide a more valuable and detailed analysis. Due to practical limitations, only those threats that recur in the prior literature have been highlighted and analysed.

Opposing views are compared in an attempt to provide a detailed analysis to answer the paper's core research question. Lastly, the conclusion provides closing arguments, highlights the paper's limitations, and suggests areas for further research.

\section{Methodology}


The paper used directed content analysis to provide greater clarity on emerging technology threats to the auditing profession, audit firms and the audit process. To focus future research questions, prior literature was used to collate, summarise, and analyse studies, which broadened the usual goal of directed content analysis, which is to extend theory (Hsieh \& Shannon, 2005).

Google Scholar and University of Cape Town library databases were used to start the online sample selection. All papers and published reports on emerging technology in auditing were identified. Relevant information was ascertained from the studies' abstracts. Supplementary information was accessed from reputable websites of the 'Big 4' audit firms and professional accounting bodies, due to the newly developing stature of emerging technology. The selected literature was then reviewed in terms of the research question.

\section{Literature review Introduction}

The literature review provides a detailed analysis of the threats facing an audit firm implementing emerging technologies into the audit process. Firstly, reasons for the choice of threats are outlined. The literature review is then divided into sections in which individual threats are analysed and placed in the context of current and prior literature.

\section{Key threats \\ Reliability, compatibility, and security of data inputs}

AI requires a significant amount of high-quality data to operate effectively. The output produced by $\mathrm{AI}$ is thus only as good as the data input. A lack of data or data of inferior quality therefore affects AI's performance levels (Obermeyer \& Emanuel, 2016).

ISA 500 requires information used to perform audit procedures to be tested for accuracy and completeness. This test can be performed either as part of the audit procedure itself or it can be carried out before using the information to perform the audit procedure; for example, testing the operating effectiveness of the controls over the preparation and maintenance of information and then using the information to perform substantive procedures (International Auditing and Assurance Standards Board, 2009). External audit evidence is generally regarded as more reliable than internally generated audit evidence, but external big data is unreliable given the limited fields stored (Cangemi \& Brennan, 2019) causing difficulties with verifying its provenance (Appelbaum, 2016). Therefore, if data is input into AI applications, auditors - unless auditing the accuracy and completeness of the data as part of their audit procedures - are first required to audit the input data for accuracy and completeness. This poses several complications for auditors as the sheer volume, complexity and variety of big data may pose a challenge over verifying its accuracy and completeness before using AI to analyse the data. The AI analysis output is therefore limited by the nature and accuracy of the data available (Hashimoto et al., 2018).

Another concern associated with data input is that the data may not be compatible with applications as it lacks structure and has no standardised labels, which may cause difficulty in collecting and merging data (Jiali \& Khondkar, 2017; Moffitt et al., 2018).

The collection, transmission and storage of personal data may also be limited or restricted due to certain laws and regulations (Zemankova, 2019).

\section{Over reliance on technology and a shortage of skills/development}

Evaluation of the data may lead to unintended consequences, which need to be balanced against the benefits realised from using AI (Kend \& Nguyen, 2020). Algorithms may identify false or misleading correlations in the data, or correlation may be confused with causation leading to inappropriate conclusions and actions (Obermeyer \& Emanuel, 2016). Users of financial statements, such as investors, may be harmed financially and reputationally if auditors arrive at inappropriate decisions based on biased algorithms (Zemankova, 2019).

Too much reliance may be placed on the application's ability without a true understanding of how the application arrived at those results. This phenomenon is referred to as the "black box effect" whereby the inputs into and outputs from the AI application can be observed but there is little to no knowledge of its internal workings (Hashimoto et al., 2018). This may be due to the auditor not having the necessary skills to understand how the applications work. 
Auditors' lack of skills and competence appears to be a significant barrier to audit firms implementing big data analytics in their audit process (Salijeni et al., 2018).

Rose et al. (2017) examined how the timing of the evaluation of analytical results from big data software affects the application of professional judgement and the ability of auditors to make decisions. Their sample included 127 audit practitioners from 'Big 4' audit firms. Their findings indicate that when analytical results from big data software are viewed before auditors have developed an expectation of the results of the analytical review procedures from traditional audit procedures, the auditors often fail to recognise patterns in the big data analytical results. The results of their study suggest that auditors derive more benefit from using big data analytical results after they have developed an expectation of the results derived from evidence obtained from traditional audit procedures. These findings could suggest that auditors lack the necessary skills to use big data analytics effectively. Audit practitioners from smaller audit firms also expressed concerns regarding a lack of knowledge (Dagilienè \& Klovienė, 2019). Similarly, Omitogun and Al-Adeem (2019) found evidence that auditors from developing countries are aware of the importance of and the need to incorporate big data analytics into the audit process, but they lack the necessary analytical skills and are unfamiliar with latest big data analytical tools.

Individuals with advanced analytical and programming skills may be needed to supplement the lack of auditors' skills. However, as more businesses adopt big data for their decision-making, audit firms may have to compete against other businesses and may find it difficult to source personnel with the required skills (Alles \& Gray, 2014). Furthermore, if auditors lack the relevant programming skills, they will have to place reliance on others to configure and maintain the programme. If programming errors have been made, the auditor may arrive at faulty judgements based on the output provided, thereby decreasing audit effectiveness (Zhang, 2019). In addition, if the programmes are not well maintained, they could be more susceptible to manipulation by hackers leading to the theft or destruction of confidential client information (Cangemi \& Brennan, 2019; Zhang, 2019).

Omitogun and Al-Adeem (2019) suggest that auditors' lack of analytical skills may be due to most accounting degrees and qualifying exams not emphasising big data analytics. Richin et al. (2017) argue that while big data analytics enhance an auditor's skills, academics, professional bodies, and regulatory bodies must make the necessary adjustments to address deficiencies in their qualifications and standards. Kend and Nguyen (2020) propose future research should consider whether accounting degrees are structured to produce graduates with the necessary skills and knowledge to perform audits using AI, robotics process automation and big data analytics.

By placing excessive reliance on AI, auditors might end up being de-skilled as they play a more passive role in making decisions with limited use of their professional judgement (Sutton et al., 2018).

Salijeni et al. (2018) question whether audit firms operating in a big data era are a suitable environment to develop professionals if analytical skills are emphasised in the future. Turley et al. (2016) and Sutton et al. (2018) note that automation of audit processes may undermine the development of professional personnel to exercise professional judgement effectively.

\section{Auditors becoming redundant or having to alter their roles}

Synergies between technology can lead to the development and adoption of new technology that can transform how things are done (Hashimoto et al., 2018).

Clohessy and Acton (2019) claim that blockchain could be a disruptive technology with a widespread impact on various businesses in the future. A 2019 Global Blockchain survey run by Deloitte had 56 percent of respondents echoing Clohessy and Acton's (2019) sentiments and believing that blockchain could potentially disrupt their businesses (Deloitte, 2019b). Blockchain use will potentially cause a shift from placing faith in people to accurately record and maintain transactions in separate ledgers to trusting the nature of the system to automatically verify and secure transactions in a decentralised digital ledger (Nofer et al., 2017). Although mainstream adoption rates are increasing (Kend \& Nguyen, 2020), the rate of adoption is still relatively low (Clohessy \& Acton, 2019).

Blockchain is a tamper-proof digital database of transactions ("a digital ledger") that requires consensus among computers on a peer-to-peer network before the transaction can be recorded in the database. The database is not centrally administered, and a copy of the database is stored on each computer in the network, making it easily viewable at all times by all users. The blocks contain digital 
information about the transaction and blocks are linked together via a chain to form a series of events. Each block uses a hash created from an algorithm (similar in concept to a unique transaction ID) that allows the data to be authenticated. Each subsequent block stores the previous block in the chain's hash. If the original data is changed, a new hash is created for the altered data causing the altered data's hash to fail to match the original data's hash (Beck, 2018; Nofer et al., 2017; Rozario \& Thomas, 2019). As data cannot practically be altered due to the nature of the system, blockchain facilitates triple-entry accounting by acting as an intermediary to automatically authenticate the transaction and thus increase the reliability and transparency of record-keeping (Dai \& Vasarhelyi, 2017).

Schmitz and Leoni (2019) performed a thematic analysis of academic literature and professional reports and the websites of the 'Big 4' audit firms and internationally recognised accounting bodies. The authors claim that the shift in trust to blockchain has led to many academics and practitioners believing that auditors will become obsolete. However, Schmitz and Leoni (2019) suggest that these claims may not be valid as blockchain only provides assurance that the transaction has been recorded, not that it has occurred. Likewise, the underlying transaction may not have been authorised (Cangemi \& Brennan, 2019). In a global survey of 600 participants, PwC (2018) reports that 45 percent of respondents believed a lack of trust in the technology could delay the adoption of blockchain. Auditors will therefore still be needed to provide assurance that the underlying transactions are valid (Cangemi \& Brennan, 2019; Schmitz \& Leoni, 2019).

Although blockchain may not cause auditors to become redundant, they will be required to fundamentally alter their role in a blockchain environment (Cangemi \& Brennan, 2019; Dai \& Vasarhelyi, 2017; Rozario \& Thomas, 2019; Schmitz \& Leoni, 2019). Firstly, blockchain could cause a shift from the traditional assurance model of auditors examining historical data to a continuous assurance model where parties, including but not limited to the auditor, share documents via blockchain and can verify the transactions in the blockchain in real-time (Cangemi \& Brennan, 2019; Dai \& Vasarhelyi, 2017; Rozario \& Thomas, 2019). While this may cause the importance of auditors in verifying certain transactions to decrease, auditors will be needed for other roles that require the exercise of professional judgement (Dai \& Vasarhelyi, 2017). For instance, if payment is recorded, the auditor's judgement will be required to determine if the corresponding contra-account has been correctly classified (ICAEW, 2017). Other roles could include providing assurance services over the system's ability to record transactions securely and maintain integrity (Boillet, 2017; Dai \& Vasarhelyi, 2017). Furthermore, auditors will need to vet external parties who provide online services for blockchain to ensure they offer reliable services according to all laws and regulations (Boillet, 2017).

Secondly, auditors will be needed to render services related to smart contracts, another blockchain application as there are claims that smart contracts will be the future of doing business (EY, 2020b). A smart contract has the contract's terms and conditions written into the source code of a program stored on the blockchain. Once certain conditions occur, the contract automatically executes (EY, 2018). Auditors could play a role in creating smart contracts that are used in a system of internal control and to examine data using sophisticated analysis techniques (Dai \& Vasarhelyi, 2017). Following EY's launch of its testing and security services for smart contracts, vulnerabilities in the source code are being identified by EY (EY, 2019). In addition to assurance services for smart contracts, auditors may offer new services related to assuring the blockchain system and validating digital assets (Deloitte, 2019a). Lastly, as the blockchain requires consensus among various users before being recorded, the recording of the transaction can easily be verified and automated. This could result in a shift for auditors from verifying the recording of transactions to focusing on aspects of the audit that cannot be automated (Boillet, 2017). Schmitz and Leoni (2019) claim that businesses mostly limit recording their transactions on blockchain to those linked to trade receivables and payables. This would suggest that auditors would still be needed to perform a traditional audit for those transactions not recorded on blockchain (Cao et al., 2019; Rozario \& Thomas, 2019). However, auditors need to be cognisant of how their roles may be adapted and thus make the necessary adjustments to adapt within a blockchain environment to remain relevant.

Emerging technology may not replace the audit outright, but it may attract non-audit firms to the audit industry, causing the traditional audit firm to become redundant. Large multi-national companies who specialise in technological innovation, such as Google, could easily leverage the capabilities of 
emerging technology and apply them in the audit process. The audit industry must therefore adequately manage the benefits and threats created by blockchain and other emerging technologies (Richins et al. 2017).

\section{Costs creating a barrier for adoption}

Emerging technology will require a significant investment in resources, both financial and nonfinancial. The 'Big 4', with their large international networks, have greater access to resources than small audit firms and will thus be better placed to service their clients' needs using emerging technology. This would decrease competition within the audit industry as resource constraints would cause small firms to struggle to remain competitive and meet their clients' expectations (Kend \& Nguyen, 2020). Cao et al. (2019) claim that there are indirect costs associated with the adoption of blockchain by auditors such as the loss of clients who prefer to be audited using traditional methods. Cao et al. (2019) suggest that despite the numerous benefits, which include a cost-saving from audit efficiency, the upfront investment costs associated with blockchain may limit its adoption by auditors.

\section{Technical standards outdated}

Salijeni et al. (2018) claim that the lack of guidance in regulations and professional standards may inhibit auditors from fully embracing and adopting technological advances. Audit practitioners noted that the regulators and standard setters may be slow to make the necessary adjustments to keep up with technological advances (Kend \& Nguyen, 2020). Rozario and Thomas (2019) suggest that it is unclear what changes should be implemented to the auditing standards to facilitate using more advanced analytical tools. Alles (2015), however, states that auditors do not use their full discretion in interpreting the requirements of the current iteration of the auditing standards and they should view big data as a means to gather audit evidence to satisfy the current auditing standards requirements, rather than as a new development that requires auditing standards to be revised to facilitate big data's use in the audit process. Regulators claim that the current iteration of auditing standards can be applied to audits using big data analytics but may need additional context for concepts such as materiality and risk assessment when considered within a big data environment (Salijeni et al., 2018).

However, Kend and Nguyen (2020) call for audit standards to be revised to facilitate the adoption of and address the threats created by the use of emerging technology by auditors. Omitogun and AlAdeem (2019) propose research to explore how professional auditing standards can provide requirements for data security and safeguards against ethical threats.

\section{Conclusion}

This paper analysed the effect of the threats created by emerging technologies on the auditing profession, audit firms and the audit process. This analysis provided value in two ways. Firstly, it helped determine how technology impacts the future of the auditing profession. Secondly, this paper helps firms assess whether to invest in new technologies by providing a comprehensive overview of the threats resulting from such a decision.

These threats relate to the reliability, compatibility and security of data input concerns, the auditor placing too great a reliance on technology, a shortage of skills required to use emerging technology effectively, the costs of emerging technology creating a potential barrier for adoption, auditors becoming redundant or having to fundamentally alter their current roles and professional auditing standards not providing adequate guidance to allow auditors to use new technologies.

In an ever-changing environment, it is of paramount importance for auditors to maintain relevance to continue to provide a valuable service. This will not only improve the overall credibility of financial statements, but it will also contribute to the long-term viability of the auditing profession. In accomplishing this, auditors will be required to address some, if not all, of these identified threats.

\section{Limitations and areas for future research}

As noted by Salijeni et al. (2018), there is limited empirical evidence on the effects of emerging technology on the audit process and profession. As such, future research could add value by performing a quantitative analysis to determine the validity of an individual threat to audit firms and the auditing profession. As no attempt has been made to determine whether the threats outweigh the benefits created 
or vice-versa, and no conclusion has been formed as to whether audit firms should engage in technological implementation, this presents scope for future research.

\section{References}

Alles, M. and Gray, G. (2014). Developing a Framework for the Role of Big Data in Auditing: A Synthesis of the Literature. Unpublished Working Paper, Rutgers Business School.

Alles, M. (2015). Drivers of the Use and Facilitators and Obstacles of the Evolution of Big Data by the Audit Profession. Accounting Horizons, 29(2), pp. 439-449.

Alpaydin, E. (2016). Machine learning: The new AI, Cambridge: MIT Press.

Appelbaum, D. (2016). Securing Big Data Provenance for Auditors: The Big Data Provenance Black Box as Reliable Evidence. Journal of emerging technologies in accounting, 13(1), pp. 17-36.

Appelbaum, D., Kogan, A. and Vasarhelyi, M. (2017). Big Data and Analytics in the Modern Audit Engagement: Research Needs. Auditing: a journal of practice and theory, 36(4), pp. 1-27.

Association of Certified Chartered Accountants, (2020). Big Data [Online]. Available at: https://www.accaglobal.com/sg/en/student/exam-support-resources/professional-exams-studyresources/p5/technical-articles/big-data.html [Accessed 1 October 2020].

Asthana, S., Khurana, I. and Raman, K. (2018). Fee competition among Big 4 auditors and audit quality. Review of quantitative finance and accounting, 52(2), pp. 403-438.

Beata, Ś. (2018). Industry 4.0 - Are we ready? Polish Journal of Management Studies, 17(1), pp. 232-248.

Beck, R. (2018). Beyond Bitcoin: The Rise of Blockchain World. Computer (Long Beach, Calif.), 51(2), pp. 54-58.

Boillet, J. (2017). Are auditors ready for blockchain? The audit profession is eyeing blockchain. Accounting today, 31(9), p. 34.

Botic, G. (2018). Protecting Investors through Change [Online]. Available at: https://pcaobus.org/News/Speech/Pages/botic-protecting-investors-through-change.aspx [Accessed 29 September 2020].

Cangemi, M. and Brennan, G. (2019). Blockchain Auditing - Accelerating the need for automated audits. EDPACS, 59(4), pp. 1-11.

Cao, S., Cong, L., Yang, B. (2019). Financial Reporting and Blockchains: Audit Pricing, Misstatements, and Regulation. Unpublished Working Paper. George State University.

Clohessy, T. and Acton, T. (2019). Investigating the influence of organizational factors on blockchain adoption: An innovation theory perspective. Industrial management + data systems, 119(7), pp. 1457-1491.

Copeland, J. (2020). What is Artificial Intelligence? [Online]. Available at: https://www.britannica.com/technology/artificial-intelligence [Accessed 30 September 2020].

Dagilienè, L. and Klovienè, L. (2019). Motivation to use big data and big data analytics in external auditing. Managerial Auditing Journal, 34(7), pp. 750-782.

Dai, J. and Vasarhelyi, M. (2017). Toward Blockchain-Based Accounting and Assurance. The Journal of information systems, 31(3), pp. 5-21.

Deloitte, (2019a). Blockchain: Inspiring an evolution in commerce [Online]. Available at: https://www2.deloitte.com/content/dam/Deloitte/fi/Documents/public-sector/us-cons-deloitteblockchain-inspiring-an-evolution-in-commerce.pdf [Accessed 6 October 2020].

Deloitte, (2019b). Deloitte's 2019 Global Blockchain Survey [Online]. Available at: https://www2.deloitte.com/content/dam/Deloitte/se/Documents/risk/DI_2019-global-blockchainsurvey.pdf [Accessed 1 October 2020].

Deloitte, (2020). Advancing Audit Quality with Smarter Audits [Online]. Available at: https://www2.deloitte.com/za/en/pages/audit/solutions/smarter-audits.html [Accessed 30 September 2020].

Deo, R. (2015). Machine Learning in Medicine. Circulation (New York, N.Y.), 132(20), pp. 1920-1930.

European Commission, (2016). The EU Data Protection Reform and Big Data: Factsheet 2016 [Online]. Available at: https://op.europa.eu/en/publication-detail/-/publication/51fc3ba6-e601-11e7-9749-01aa75ed71a1 [Accessed 30 September 2020].

EY, (2018). Smart contracts using blockchain technology: a better way to deliver construction contracts [Online]. Available at: https://assets.ey.com/content/dam/ey-sites/ey-com/en_ca/topics/blockchain/ey-how-blockchain-canenable-smarter-contracts-ininfrastructure.pdf?download\#: :text=A\%20smart\%20contract\%20is\%20essentially,code\%20working \%20on \%20 a\%20network. [Accessed 6 October 2020].

EY, (2019). EY launches smart contract testing service for blockchain clients [Online]. Available at: https://www.ey.com/en_gl/news/2019/04/ey-launches-smart-contract-testing-service-for-blockchain-clients [Accessed 6 October 2020]. 
EY, (2020a). Audit innovation [Online]. Available at: https://www.ey.com/en_gl/audit/innovation [Accessed 30 September 2020].

EY, (2020b). Blockchain platforms [Online]. Available at: https://www.ey.com/en_gl/blockchain/blockchain-platforms [Accessed 6 October 2020].

Favaretto, M., De Clercq, E., Schneble, C. and Elger, B. (2020). What is your definition of Big Data? Researchers' understanding of the phenomenon of the decade. PloS one, 15(2), pp. 120.

Ferguson, L. (2016). The Importance of Planning and Time Management in Audit Quality [Online]. Available at: https://pcaobus.org/News/Speech/Pages/Ferguson-audit-planning-Institute-12-13-15.aspx [Accessed 29 September 2020].

Gandomi, A. and Haider, M. (2015). Beyond the hype: Big data concepts, methods, and analytics. International journal of information management, 35(2), pp. 137-144.

Gartner, (2012). Gartner Glossary - Big Data [Online]. Available at: https://www.gartner.com/en/informationtechnology/glossary/big-data [Accessed 30 September 2020].

Harris, S. (2016). Issues for the Academic Community to Consider [Online]. Available at: https://pcaobus.org/News/Speech/Pages/Steve-Harris-speech-PCAOB-AAA-conference-2016.aspx [Accessed 29 September 2020].

Harris, S. (2017). Technology and the Audit of Today and Tomorrow [Online]. Available at: https://pcaobus.org/News/Speech/Pages/Harris-statement-PCAOB-AAA-4-20-17.aspx [Accessed 29 September 2020].

Hashimoto, D., Rosman, G., Rus, D. and Meireles, O. (2018). Artificial Intelligence in Surgery: Promises and Perils. Annals of Surgery, 268(1), pp. 70-76.

Institute of Chartered Accountants in England and Wales, (2017). Blockchain and the future of accountancy [Online]. Available at: https://www.icaew.com/technical/technology/blockchain/blockchain-articles/blockchain-andthe-accounting-perspective [Accessed 7 October 2020].

Institute of Electrical and Electronics Engineers Standards Association Corporate Advisory Group, (2017). IEEE Guide for Terms and Concepts in Intelligent Process Automation. New York: IEEE.

International Auditing and Assurance Standards Board, (2009). ISA 500: Audit Evidence. In: South African Institute of Chartered Accountants (ed.) SAICA Members' Handbook. 2019/2020 ed. Pietermaritzburg: LexisNexis

Jiali, T. and Khondkar, E. (2017). BIG DATA in Business Analytics: Implications for the Audit Profession. The CPA Journal (1975), 87(6), pp. 34-39.

Kend, M. and Nguyen, L. (2020). Big Data Analytics and Other Emerging Technologies: The Impact on the Australian Audit and Assurance Profession. Australian Accounting Review. 90(0), pp. 1-14.

KPMG, (2020). Audit Innovation [Online]. Available at: https://home.kpmg/us/en/home/services/audit/auditinnovation.html [Accessed 30 September 2020].

Moffitt, K., Rozario, A. and Vasarhelyi, M. (2018). Robotic Process Automation for Auditing. Journal of emerging technologies in accounting, 15(1), pp. 1-10.

National Science Foundation, (2012). Core Techniques and Technologies for Advancing Big Data Science \& Engineering (BIGDATA) [Online]. Available at: https://www.nsf.gov/pubs/2012/nsf12499/nsf12499.pdf [Accessed 30 September 2020].

National Science Foundation, (2014). Critical Techniques and Technologies for Advancing Big Data Science \& Engineering (BIGDATA) [Online]. Available at: https://www.nsf.gov/pubs/2014/nsf14543/nsf14543.pdf [Accessed 30 September 2020].

Nofer, M., Gomber, P., Hinz, O. and Schiereck, D. (2017). Blockchain. Business \& information systems engineering, 59(3), pp. 183-187.

Obermeyer, Z. and Emanuel, E. (2016). Predicting the Future - Big Data, Machine Learning, and Clinical Medicine. The New England journal of medicine, 375(13), pp. 1216-1219.

Omitogun, A. and Al-Adeem, K. (2019). Auditors' Perceptions of and Competencies in Big Data and Data Analytics: An Empirical Investigation. International Journal of Computer Auditing, 1(1), pp. 92-113.

Persellin, J., Schmidt, J., Vandervelde, S. and Wilkins, M. (2019). Auditor Perceptions of Audit Workloads, Audit Quality, and Job Satisfaction. Accounting horizons, 33(4), pp. 95-117.

PwC, (2018). PwC's Global Blockchain Survey [Online]. Available at: https://www.pwc.com/gx/en/industries/technology/blockchain/blockchain-in-business.html [Accessed 1 October 2020].

PwC, (2019). Harnessing the power of AI to transform the detection of fraud and error [Online]. Available at: https://www.pwc.com/gx/en/about/stories-from-across-the-world/harnessing-the-power-of-ai-totransform-the-detection-of-fraud-and-error.html [Accessed 30 September 2020].

Quarteroni, S. (2018). Natural Language Processing for Industry: ELCA's experience. Informatik-Spektrum, 41(2), pp. 105-112. 
Richins, G., Stapleton, A., Stratopoulos, T. and Wong, C. (2017). Big data analytics: Opportunity or threat for the accounting profession? Journal of Information Systems, 31(3), pp. 63-79.

Rose, A., Rose, J., Sanderson, K. and Thibodeau, J. (2017). When Should Audit Firms Introduce Analyses of Big Data into the Audit Process? The Journal of information systems, 31(3), pp. 81-99.

Rozario, A. \& Thomas, C. (2019). Reengineering the Audit with Blockchain and Smart Contracts. Journal of emerging technologies in accounting, 16(1), pp. 21-35.

Salijeni, G., Samsonova-Taddei, A. and Turley, S. (2018). Big Data and changes in audit technology: contemplating a research agenda. Accounting and business research, 49(1), pp. 95-119.

Schmitz, J. and Leoni, G. (2019). Accounting and Auditing at the Time of Blockchain Technology: A Research Agenda. Australian Accounting Review, 29(2), pp. 331-342.

Schwab, K. (2016). The Fourth Industrial Revolution: what it means, how to respond [Online]. Available at: https://www.weforum.org/agenda/2016/01/what-is-the-fourth-industrial-revolution/ [Accessed 29 September 2020].

Sutton, S., Arnold, V. and Holt, M. (2018). How Much Automation Is Too Much? Keeping the Human Relevant in Knowledge Work. Journal of emerging technologies in accounting, 15(2), pp. 15-25.

Szeliski, R. (2011). Computer vision: algorithms and applications, London: Springer.

Turley, S., Humphrey, C., Samsonova-Taddei, A., Siddiqui, J., Woods, M., Basoudis, I. and Richard, C. (2016) Skills, competencies, and the sustainability of the modern audit [Online]. Available at: https://www.icas.com/_data/assets/pdf_file/0010/239455/Skills-competencies-and-the-Sustainability-ofmodern-audit.pdf [Accessed 4 October 2020].

Veerankutty, F., Ramayah, T. and Ali, N. (2018). Information Technology Governance on Audit Technology Performance among Malaysian Public Sector Auditors. Social sciences (Basel), 7(8), p. 124.

Zemankova, A. (2019). Artificial Intelligence in Audit and Accounting: Development, Current Trends, Opportunities and Threats - Literature Review. 2019 International Conference on Control, Artificial Intelligence, Robotics \& Optimization (ICCAIRO), 8-10 Dec, pp. 148-154.

Zhang, C. (2019). Intelligent Process Automation in Audit. Journal of emerging technologies in accounting, 16(2), pp. 6988. 